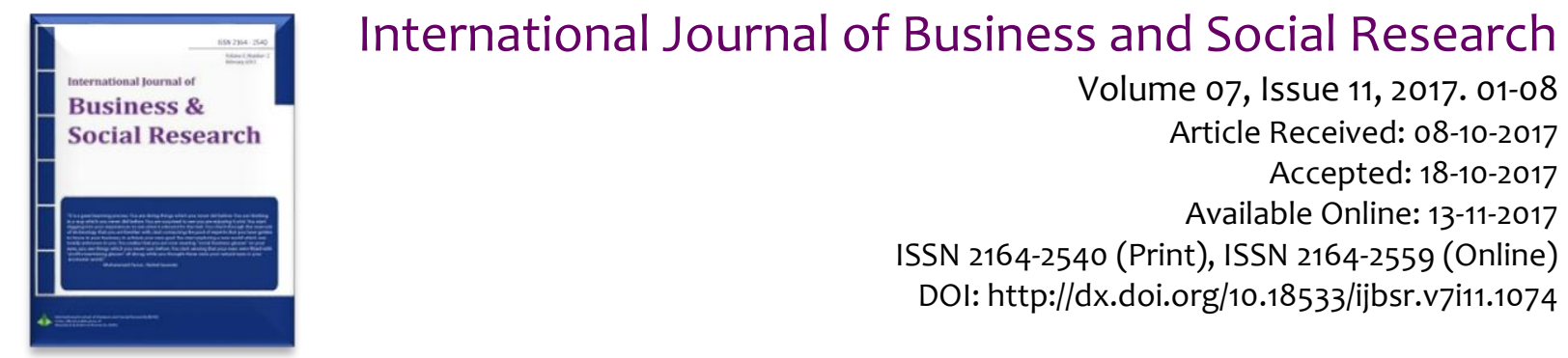

\title{
A Conceptual Framework of a Customer's Perception of Retail Salesperson Opportunism
}

\author{
Sarah Magnotta ${ }^{1}$
}

\begin{abstract}
A customer's perception of salesperson opportunism reflects the extent to which a customer believes that a salesperson is intentionally self-interest seeking with little regard for the consequences to the customer. While the marketing literature is rich with research examining salesperson opportunism from the managerial perspective, the consumer's perspective is underdeveloped. The customer's perception is important, such that it has implications for purchasing intentions, as well as satisfaction with the salesperson and retailer. In this research, a conceptual framework of a customer's perception of salesperson opportunism is developed. Further, propositions are set forth which provide scope, and allow for future empirical testing, of this domain. The implications of the framework and fruitful areas of potential research are discussed.
\end{abstract}

Keywords: Conceptual, Opportunism, Persuasion Knowledge, Sales.

JEL Codes: M12, M31, M37.

This is an open access article under Creative Commons Attribution 4.0 License, 2017.

\section{Introduction}

According to the Bureau of Labor Statistics, there are 4.5 million retail salespeople employed in the U.S. as of March 2017 (Occupational Employment 2017). Friestad and Wright (1994) suggest that customers are aware that these retail salespeople are attempting to persuade their purchase behavior, but it is unclear the extent to which customer perceive that the salesperson is attempting to persuade while also taking undue advantage of the customer. While salespeople and their retailers likely shield the customer from the specific incentives being offered to a salesperson and the motives directing a salesperson's behavior, the customer has likely developed a general perception of salesperson opportunism (e.g., Buell \& Norton, 2011; Friestad \& Wright, 1994). A customer's perception of salesperson opportunism is defined here as the extent to which a customer believes that a salesperson is intentionally self-interest seeking with little regard for the consequences to the customer (e.g., Handley \& Angst, 2015; John, 1984; Williamson, 1975; Zeng, Chi, Dong, \& Huang, 2017). Previous research suggests that the customer's perception of the salesperson has a large impact on the customer's purchasing behavior and satisfaction with the salesperson (e.g., Mallalieu, 2006). Importantly, a perception of salesperson opportunism is likely to pique the customer's assumptions regarding sales encounters, and have 'spillover effects' such that it impacts the customer's satisfaction with the retailer. Further, it may shift the locus

${ }^{1}$ Assistant Professor, Marketing, Towson University, Email: smagnotta@towson.edu 
of blame for the salesperson's opportunistic behaviors onto the retailer (e.g., Baumeister, Scherer, \& Wangenheim, 2015).

The expansive sales performance literature has addressed the characteristics of a salesperson that ultimately lead to salesperson success, such as trustworthiness (Campbell, Davis \& Skinner, 2006), ability to develop a rapport (Doney \& Cannon, 1997), and adaptive selling skills (Park \& Holloway, 2003) as viewed from the perspective of the salesperson, firm, or colleague. Despite this valuable research, there has been little focus on the customer's perception of the salesperson and its outcomes on salesperson and retailer success.

This research proposes a conceptual framework of a consumer's perception of salesperson opportunism, and maps its impact on utilization of the customer's persuasion knowledge (Friestad \& Wright, 1994) and subsequent blame for the opportunistic behavior displaced to the retailer. This research suggests that the focal construct impacts the extent to which a customer utilizes their persuasion knowledge (Buell \& Norton, 2011; Friestad \& Wright, 1994). Yet, this relationship is contingent upon explicit cues regarding a salesperson's ability to behave opportunistically towards a customer. Interestingly, it is suggested that opportunism triggers present within the encounter (e.g., salespeople explicitly stating that they are not on commission) moderate the relationship between perceptions of opportunism and utilization of persuasion knowledge. The framework further suggests a spillover effect of salesperson opportunism, such that the locus of blame for the salesperson's behavior is shifted to the retailer.

This paper begins with a theoretical background of the focal concepts and theories, followed by the development of a set of three novel propositions. Last, there is a discussion of implications and limitations, as well as areas of fruitful future research.

\section{Background}

The focal topic of this research is the customer's perception of salesperson opportunism. Opportunism within the field of marketing is grounded in transaction cost economics, agency theory, and relationship marketing (Jap \& Anderson, 2003; Sa Vinhas \& Heide, 2014; Williamson, 1975). Firms can utilize incentives, compensation, monitoring, contracts, and social norms to align the goals of others with their own goals in an effort to minimize opportunistic behavior by suppliers, buyers, and employees (Brown, Dev, \& Lee, 2000). Firms must protect themselves prior to forming relationships in situations where they do not have perfect information of the other party, as well as after forming relationships in situations where they have less power and are likely to be dominated by the other party. Opportunistic behavior is of great cost to organizations in both the need to dedicate resources towards control and monitoring behaviors, as well as the opportunity costs of deals that are not done as a result of perceptions of opportunism by either party (Wathne \& Heide, 2000). Opportunism can take two forms: passive, such as shirking on commitments or refusal to adapt within a situation, or active such as purposefully misguiding or extracting concessions from the other party (Wathne \& Heide, 2000). We focus here on active opportunism, in which the salesperson purposefully persuades their customer to purchase a suboptimal product, due to its relevance to the retail sales context.

Like the firm-to-firm relationships discussed above, individual salespeople are presented with countless opportunities to act opportunistically during a sales encounter with a customer, such as recommending products that ignore customer needs or recommending products with the highest potential commission. John (1984) argued against claims that opportunistic behavior is human nature and that is instinctual to seek unrestrained self-interest maximization. Information asymmetry, or the limitation of one party to recognize opportunistic behavior of the other, and lock-in conditions increase the likelihood of opportunistic behavior by salespeople (John, 1984). A lock-in condition refers to a situation in which one party has no alternatives or substitutes and cannot meet their goals outside of the particular relationship. John (1984) further suggests that increased communication and minimized bureaucracy within the governance structure can mitigate opportunistic behavior. Alternatively, Anderson (1988) suggests that investments in a salesperson can lead to opportunistic behavior, and as the difficulty in evaluating a salesperson increases, the salesperson is more likely to act opportunistically. It is suggested that compensation systems can be designed to minimize the potential of salesperson opportunism (Mallin, O'Donnell, \& Hu, 2010) by rewarding the behavior that is desired by the firm. Outcomes of salesperson opportunistic behavior include a reduction in positive reputation (Nunlee, 
2004) and termination of relationships (Wathne \& Heide, 2000). Further, Murtha, Challagalla, and Kohli (2011) studied the concern of potential opportunism rather than the perception of existing opportunism and suggest that the concern can reduce team-building behaviors by increasing the likelihood of blocking. The perception of salesperson opportunism has been explored, to this point, from the salesperson, firm, or colleague perspective, yet the important and impactful notion of salesperson opportunism from the customer perspective has been underdeveloped.

Salesperson opportunism from a customer's perspective is likely to be related to, but differ from, several research streams within the selling literature, namely, customer skepticism, customer perceptions of salesperson trustworthiness, and salesperson ethical behavior. Customer skepticism in advertising is defined as "the tendency toward disbelief of advertising claims" (Obermiller, Spangenberg, \& MacLachlan, 2005). Skepticism has been shown to vary across individuals and have an impact on persuasability (Obermiller \& Spangenberg, 1998). Customer skepticism differs from perceptions of salesperson opportunism such that skepticism lacks the element of guile, or purposefully taking advantage of the customer.

Importantly, Oates, McDonald, Alevizou, Hwant, Young, and McMorland (2008) suggest that salespeople have more influence on a buyer than do other people (family, friends, reviewers) and that influence increases in the presence of trust within a customer-salesperson relationship. To that end, Doney and Cannon (1997) find that there are several key elements contributing to salesperson trust, such as expertise, power, likeability, similarity, frequent business contacts, frequent social contacts, and the perceived length of the relationship. A lack of customer trust in a salesperson differs from perceptions of opportunism in a salesperson, such that trust is unobservable while opportunism is generally based on observable, specific actions (Jap \& Anderson, 2003).

Relatedly, previous research has suggested that there are several conditions of retail sales jobs that allow for unethical behavior. These conditions include autonomy, pressure to perform, and sales encounters which foster dishonesty and exaggeration (Lagace, Dahlstrom, \& Gassenheimer, 1991). Unethical salespeople may misrepresent products by exaggerating or lying, may lie about their own product knowledge, or may make promises they cannot keep. A customer's perception of a salesperson's ethics differs from perceptions of opportunism in that ethical behavior isn't necessarily in pursuit of selfinterest, and is a trait about a salesperson that transcends the selling encounter. Additionally, unethical behaviors by a salesperson do not directly infer that the salesperson is taking advantage of the customer, but may be taking advantage of other entities as well. In the following section, the aforementioned literature is integrated to develop an overarching framework (Figure 1) of a customer's perception of salesperson opportunism.

Figure 1: Conceptual framework

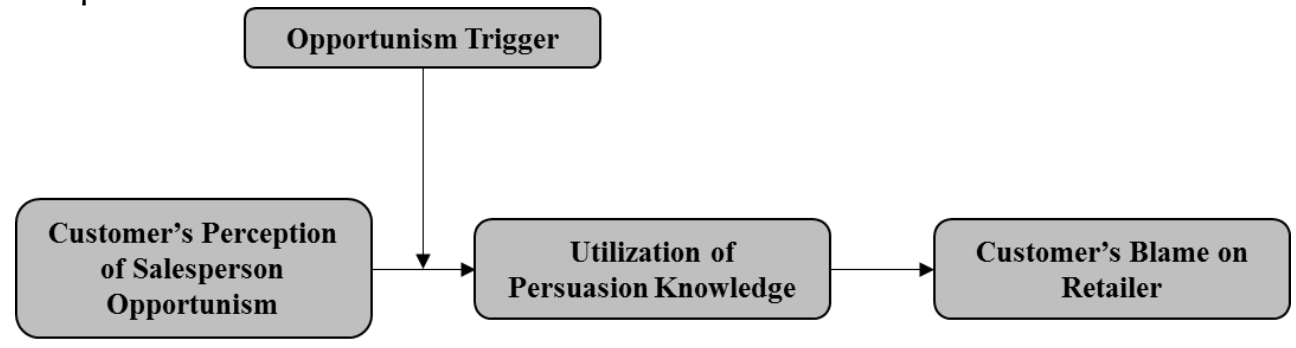

\section{Conceptual framework development}

The Persuasion Knowledge Model (Friestad \& Wright, 1994) suggests that customers enter a sales encounter with varying degrees of three key types of knowledge: topic knowledge, persuasion knowledge, and agent knowledge. Topic knowledge includes the customer's knowledge of the product and their own expertise with the product category. Persuasion tactics knowledge includes the customer's beliefs about marketer's tactics and general strategies of persuasion. And most importantly for this line of research, agent knowledge includes the customer's knowledge of a particular salesperson's traits, competencies, and motives (or knowledge of the traits, competencies, and motives of salespeople in general). When a customer encounters a particular salesperson for the first time, the customer is able to draw upon their own cognitive skills, prior experiences in similar sales situations, and 
conversations with others to develop agent knowledge in a given context, even when they haven't met that salesperson before (Campbell \& Kirmani, 2008). This is akin to someone knowing how to behave in a given medical situation and having expectations regarding the level of care provided, even if they haven't met the particular doctor officer before, due to previous personal experiences or experiences of friends and family.

Previous research has identified several factors that influence utilization of persuasion knowledge, including salesperson credibility (Karmarkar \& Tormala, 2010) and customer experience (Campbell \& Kirmani, 2008). The framework developed here suggests that when a customer has a strong perception of salesperson opportunism, they are more likely to utilize their persuasion knowledge and cognitively evaluate their own topic knowledge, persuasion tactics knowledge, and salesperson motive knowledge.

Further, Friestad and Wright (1994) suggest that perceived conflicts of interest increase utilization of persuasion knowledge. A customer may perceive high salesperson opportunism if they believe the salesperson is conflicted between aptly serving the customer while earning the highest possible commission. Alternatively, when a customer's perception of salesperson opportunism is low, they are less likely to utilize their persuasion knowledge. For example, when a customer does not suspect that the salesperson has the ability to act opportunistically, they are less likely to activate previous sales encounters and experiences to develop a plan for how to proceed, such that the customer is able to take the current sales encounter at face value. Following this logic:

$\mathrm{P}_{1}$ : There is a positive relationship between a customer's perceptions of salesperson opportunism and utilization of persuasion knowledge.

\subsection{Opportunism trigger moderator}

This research examines the relationship between a customer's perception of salesperson opportunism and their utilization of persuasion knowledge. Interestingly, previous research suggests that there are conditions under which that relationship varies (e.g., Campbell \& Kirmani, 2000). Thus, a moderator variable is included in the framework which helps to define the relationship between the key variables (Baron \& Kenny, 1986). More specifically, we examine the impact of an explicit trigger regarding the salesperson's ability to behave opportunistically.

Retailers often choose a sales strategy which involves sending a trigger signal to customers that the retailer is oriented towards helping the customer rather than orientated towards increasing sales. These triggers may be explicit or implicit. Explicit triggers are those in which the retailer or salesperson directly addresses the potential conflict of interest (e.g., commission). For example, retailers may blatantly deny providing commissions to salespeople in national advertising, as is commonplace at some major car dealerships. Or, a retailer may rely on salespeople to express to customers that they do not work on commission, as is common in clothing retailers. Alternatively, implicit triggers are demonstrated by a retailer or salesperson emphasizing their commitment to customer needs and preferences. Interestingly, the impact of these highly-prevalent triggers are not well understood in the marketing literature.

When a trigger is present (e.g., a salesperson says "I do not work on commission"), it sends a message to the customer that the salesperson should be acting in the customer's best interest, such that they do not have the ability to act opportunistically. The trigger activates the customer's utilization of their persuasion knowledge such that an individual who does not have a high perception of salesperson opportunism is made more aware of the fact that salesperson work under a variety of motives and therefore activates their persuasion knowledge more so than if there were no trigger present. Counterintuitively, this suggests that the presence of the triggers increases the likelihood that the unsuspicious customer will activate their persuasion knowledge when confronted with a reminder that salespeople in other situations may be acting opportunistically.

Alternatively, customers with an increasing (high) perception of salesperson opportunism activate their persuasion knowledge, such that the trigger has less of an impact than it does with an unsuspicious customer. Based on this logic:

$\mathrm{P}_{2}$ : The positive relationship between a customer's general perception of salesperson opportunism and utilization of persuasion knowledge depends upon opportunism triggers such 
that the relationship is less positive when a trigger is present and more positive when there is no trigger present.

\subsection{Blame on retailer}

Customers with activated persuasion knowledge are likely to infer the source of the salesperson's behavior and product recommendation. Previous research in this area has explored customers' perception of intrinsic and extrinsic motivations for a salesperson's recommendations (Sparkman 1982; Wiener \& Mowen, 1986), such that salespeople may recommend a product simply because they like it (intrinsic) or because it offers the highest incentive (extrinsic). When multiple agents of products are involved (i.e., salespeople and retailers), there is increased complexity regarding which agent is the true cause of opportunistic behavior (Folkes, 1988). For example a salesperson may be passively opportunistic on their own will (e.g., recommending a particular product because they are too lazy to uncover customers) (Wathne \& Heide, 2000).

Alternatively, a salesperson may be actively opportunistic due to the retailer's policies (e.g., recommending a particular product because it has the highest commission rather than its fulfillment of customer needs). Attribution theory suggests that the locus of blame (in this case, salesperson or retail) is based on a customer's assessment of whether or not the same action would have occurred without a particular entity's involvement (Lord \& Smith, 1983). For example, a customer may internally debate the likelihood of the salesperson behaving this way regardless of the retailer's policies regarding commissions.

As the customer's persuasion knowledge is utilized, they cognitively evaluate their persuasion tactics knowledge and salesperson motive knowledge. The customer is more aware of the tactics being used in the sales encounter, as well as the salesperson's potential motives. The cognitive evaluation of the salesperson's motives makes the customer more likely to place blame on the retailer for (1) enabling the salesperson to act opportunistically, and/or (2) encouraging the salesperson to act opportunistically by offering a compensation or motivation plan that entices the salesperson to act in self-interest. Following this logic:

$\mathrm{P}_{3}$ : There is a positive relationship between utilization of persuasion knowledge and the blame customers place on the retailer.

\section{Discussion}

The goal of this research is to examine the underdeveloped area of customer perceptions of salesperson opportunism, and suggest propositions that move this area forward in the marketing literature. The framework developed here suggests that the customer's perception of salesperson opportunism will be positively related to a customer's utilization of persuasion knowledge, and that the relationship is moderated by opportunism triggers. It is also expected that the utilization of persuasion knowledge will increase the likelihood of a customer shifting blame to the retailer for an individual salesperson's opportunistic behaviors.

This framework has meaningful implications for practitioners in retail and business-to-business sales settings. Customer's perceptions of salesperson opportunism are grounded in the notion that salespeople are purposefully taking advantage of customers with the intention of benefiting themselves (Williamson, 1979). In the event of salesperson opportunism, managers should implement training programs that properly train salespeople how to address customer needs, even in transaction-based exchanges, to reduce the perception of opportunism among customers. This framework also suggests that by minimizing triggers, customers will be less likely to draw upon their persuasion knowledge, which may have negative implications for the retailer.

To the best of the author's knowledge, there is no scale or study to date which examines the impact of a customer's perception of salesperson opportunism. As such, this study posits the initial phase of the development of a valid scale to test these propositions. The scale development process would involve generation of items adapted from existing opportunism (and related) scales (e.g., Anderson, 1988; Obermiller et al., 2005; Obermiller \& Spangenberg, 1998). Recommended seven-point Likert scale items may include the extent to which respondents believe that salespeople (or the salesperson) takes advantage of the customer, exaggerates features and benefits, are unconcerned with the needs others, 
push inappropriate products onto customers, put their interests before anyone else's, and takes advantage of the trust offered by the customer. The perception of opportunism would be measured after the respondent is exposed to one of the two conditions (i.e., trigger present, no trigger present). For example, in the 'trigger present' condition, respondents may be asked to imagine that they have entered a store to purchase a digital camera, and are approached by a salesperson that introduces themselves and states that they are not on commission. The 'no trigger present' would be a similar scenario, without the explicit acknowledgement of commission.

Notably, it is beyond the scope of this framework to specify if a customer's perception of salesperson opportunism is universal, such that it is their perception of all salespeople, or if it is specific to a particular sales encounter. Doing so may require two complementary scales, one for general perception and one specific to an encounter.

\section{Conclusion, limitations, and future research}

This research contributes to the existing literature in two key ways. First, the notion of salesperson opportunism from the customer's perspective is introduced, defined, and examined from a theoretical perspective. Second, a framework is developed which demonstrates the positioning of a customer's perception of salesperson opportunism within the retailing and sales literature. Third, the potential of a spillover effect is explored, such that the impact of salesperson opportunism extends beyond implications for the salesperson, to impact the retailer as well.

As with all research, the framework developed here has limitations, as it intended to establish a starting point for further research in this area. First, the framework suggests theoretical propositions which can be empirically validated in a future project. As alluded to above, following the establishment of a valid measure(s), future research may assess a customer's general feelings towards salesperson opportunism as it relates to salesperson opportunism in a specific encounter.

In addition, there are many important outcomes of salesperson performance that are not integrated into the present framework. For example, future research may examine the impact of a customer's perception of salesperson opportunism on purchase intentions, objective sales performance, customer satisfaction with the salesperson (e.g., Mallalieu, 2006; Nunlee, 2004), customer satisfaction with the retailer, and intentions to visit the retailer in the future (e.g., Wathne \& Heide, 2000).

In addition, given the extensive research on salesperson opportunism from the salesperson's, firm's, or colleague's (Murtha et al., 2011) perspective, future research may examine the extent to which actual opportunism (self-reported opportunism from the salesperson) aligns with a customer's, or retailers, perception of salesperson opportunism, such that the implications are far more positive when the customer, firm, or other colleagues are unaware of actual opportunism.

Additionally, managers may be interested in reducing the blame placed on the retailer, as this has negative implications for purchase intentions, satisfaction, and future visits by the customer, in which they may have encountered a completely different, less opportunistic salesperson. Indeed, previous research suggests that if managers were able to enhance the sales experience by reducing perceptions of opportunism among the salesforce, the customer's engagement with the retailer would increase (e.g., Keller, 2001; Banahene, 2017), thereby increasing the likelihood that they are a repeat purchaser and share their experience with others (e.g., Riivits-Arkonsuo \& Leppman, 2015).

Finally, previous research suggests two forms of opportunism: active and passive (Wathne \& Heide, 2000) Active opportunism may be demonstrated by a salesperson recommending a product based on the incentives available, while passive may be demonstrated by a salesperson being lazy and not incorporating customer needs into their recommendation. Future research may examine the variation in satisfaction with the salesperson or retailer dependent upon the opportunism being active, such that it is likely to have stronger negative effects under active conditions as opposed to passive conditions.

\section{References}

Anderson, E. (1988). Transaction costs as determinants of opportunism in integrated and independent sales forces. Journal of Economic Behavior and Organization, 9 (3), 247-264.

Banahene, S. (2017). The impact of brand personality and students' self-concept on brand engagement. International Journal of Business and Social Research, 7 (8), 12-25. 
Baron, R. M., \& Kenny, D. A. (1986). Moderator-mediator variables distinction in social psychological research: Conceptual, strategic, and statistical considerations. Journal of Personality and Social Psychology, 51 (6), 1173-82.

Baumeister, C., Scherer, A. \& Wangenheim, F. (2015). Branding access offers: The importance of product brands, ownership status, and spillover effects to parent brands. Journal of the Academy of Marketing Science, 43 (5), 574-588.

Brown, J. R., Dev, C.S. \& Lee, D. (2000). Managing marketing channel opportunism: the efficacy of alternative governance mechanisms. Journal of Marketing, 64 (2), 51-65.

Buell, R. W. \& Norton, M. I. (2011). The labor illusion: How operational transparency increases perceived value. Management Science, 57 (9), 1564-1579.

Campbell, K., Davis, L., \& Skinner, L. (2006). Rapport management during the exploration phase of the salesperson-customer relationship. Journal of Personal Selling and Sales Management, 26 (4), 359-370.

Campbell, M. C., \& Kirmani, A. (2008). I know what you're doing and why you're doing it: the use of the persuasion knowledge model in consumer research. Handbook of consumer psychology, 549-574.

Doney, P., \& Cannon, J. (1997). Trust in buyer-seller relationships. Journal of Marketing, 61 (April), 35-51.

Folkes, V. (1988). Recent attribution research in customer behavior: A review and new directions. Journal of Customer Research, 14 (4), 548-565.

Friestad, M., \& Wright, P. (1994). The persuasion knowledge model: How people cope with persuasion attempts. Journal of Customer Research, 21 (1), 1-30.

Friestad, M., \& Wright, P. (1995). Persuasion knowledge: Lay people's and researcher's beliefs about the psychology of advertising. Journal of Consumer Research, 22 (1), 62-74.

Handley, S. M., \& Angst, C. M. (2015). The impact of culture on the relationship between governance and opportunism in outsourcing relationships. Strategic Management Journal, 36 (9), 1412-1434.

Jap, S., \& Anderson, E. (2003). Safeguarding interorganizational performance and continuity under ex post opportunism. Management Science, 49 (12), 1684-1701.

John, G. (1984). An empirical investigation of some antecedents of opportunism in a marketing channel. Journal of Marketing Research, 21 (August), 278-289.

Karmarkar, U., \& Tormala, Z. (2010). Believe me, I have no idea what I'm talking about: The effects of source certainty on customer involvement and persuasion. Journal of Customer Research, 36 (April), 1033-1049.

Lagace, R., Dahlstrom, R., \& Gassenheimer, J. (1991). The relevance of ethical salesperson behavior on relationship quality: The pharmaceutical industry. Journal of Personal Selling and Sales Management, 11 (4), 39-47.

Lord, R., \& Smith, J. (1983). Theoretical information processing and situational factors affecting attribution theory models of organizational behavior. Academy of Management Review, 8 (1), 50-60.

Mallalieu, L. (2006). Consumer perception of salesperson influence strategies: an examination of the influence of consumer goals. Journal of Consumer Behaviour, 5 (3), 257-268.

Mallin, M., O'Donnell, E., \& Hu, M. (2010). The role of uncertainty and sales control in the development of sales manager trust. Journal of Business \& Industrial Marketing, 25 (1), 30-42.

Murtha, B., Challagalla, G., \& Kohli, A. (2011). The threat from within: Account managers' concern about opportunism by their own team members. Management Science, 57 (9), 1580-1593.

Nunlee, M. (2004). The control of intra-channel opportunism through the use of inter-channel communication. Industrial Marketing Management, 34 (5), 515-525.

Oates, C., McDonald, S., Alevizou, P., Hwant, K., Young, W., \& McMorland, L. (2008). Marketing sustainability: Use of information sources and degrees of voluntary simplicity. Journal of Marketing Communications, 14 (5), 351-365.

Obermiller, C., \& Spangenberg, E. (1998). Development of a scale to measure customer skepticism toward advertising. Journal of Customer Psychology, 7 (2), 159-186.

Obermiller, C., Spangenberg, E., \& MacLachlan, D. (2005). Ad skepticism. Journal of Advertising, 34 (3), 717.

Occupational Employment and Wages News Release (2017, March 31). Retrieved from https://www.bls.gov/news.release/ocwage.htm. 
Park, J., \& Holloway, B. (2003). Adaptive selling behavior revisited: An empirical examination of learning orientation, sales performance and job satisfaction. Journal of Personal Selling and Sales Management, 23 (3). 239-251.

Riivits-Arkonsuo, I., \& Leppiman, A. (2015). Antecedents of online word-of-mouth and memorable experience concept. International Journal of Business and Social Research, 5 (9), 1-14.

Sa Vinhas, A., \& Heide. J. (2014). Forms of competition and outcomes in dual distribution channels: The distributor's perspective. Marketing Science, 34 (1), 160-175.

Sparkman, Jr, R. M. (1982). The discounting principle in the perception of advertising. Advances in consumer research, 9 (1).

Wathne, K., \& Heide, J. (2000). Opportunism in interfirm relationships: Forms, outcomes, and solutions. Journal of Marketing, 64 (4), 36-51.

Wiener, J. L., \& Mowen, J. C. (1986). Source credibility: On the independent effects of trust and expertise. ACR North American Advances, 306-310.

Williamson, O. E. (1975). Markets and hierarchies: Analysis and antitrust implications. New York: The Free Press.

Williamson, O. E. (1979). Transaction-cost economics: The governance of contractual relations. The journal of Law and Economics, 22 (2), 233-261.

Zeng, F., Chi, Y., Dong, M.C., \& Huang, J. (2017). The dyadic structure of exchange partners' governingagency social capital and opportunism in buyer-supplier relationships. Journal of Business Research, 78 (September), 294-302. 